\title{
McKesson Health Record System
}

National Cancer Institute

\section{Source}

National Cancer Institute. McKesson Health Record System. NCI Thesaurus. Code C105671.

Any of the electronic health record systems and solutions developed by the McKesson corporation. 